\title{
Correction to: Social Organization and Subcaste Specialization in the Leaf-Cutting Ant Acromyrmex subterraneus (Formicidae: Myrmicinae)
}

\author{
Ana C. Calheiros • Mariane U. V. Ronque • \\ Paulo S. Oliveira (iD) \\ Published online: 20 November 2019 \\ C) Springer Science+Business Media, LLC, part of Springer Nature 2019
}

\section{Correction to: J Insect Behav https://doi.org/10.1007/s10905-019-09729-6}

The original version of this article unfortunately contained some mistakes for the greek letter " $\Theta$ " were unconverted which resulted to missing " $\theta$ " in the proof manuscript.

The formula appearing in column 1 of page 4 of the paper that should be read $\Theta=1-(\mathrm{N} 1 / \mathrm{i})$.

In paragraph "Where " $\Theta$ " is the sampling coverage, " $\mathrm{N}_{1}$ " is the number of behavioral acts observed only once, and " $i$ " the total of acts observed. Values of $\Theta$ between 0.90 and 1 indicate that sampling has reached sufficiency. The closer $\Theta$ approaches 1, the probability of observing a new behavioral act is low, and the more complete the sample coverage (Fagen and Goldman 1977)."

The same mistake appears in the legend of Table 1, and in the last row of the first column of Table 1 to read "Sampling coverage $(\Theta)$ follows Fagen and Goldman (1977); the closer $\Theta$ approaches 1, the more complete the sample coverage."

Last row of the first column of Table 1 that should be read as "Sampling Coverage ( $\Theta)$ ".

The original article has been corrected.

The online version of the original article can be found at https://doi.org/10.1007/s10905-019-09729-6

A. C. Calheiros - M. U. V. Ronque

Progama de Pós-Graduação em Ecologia, Instituto de Biologia, Universidade Estadual de Campinas, C. P. 6109, Campinas, SP 13083-862, Brazil

P. S. Oliveira $(\bowtie)$

Departamento de Biologia Animal, Universidade Estadual de Campinas, C. P. 6109, Campinas, SP 13083-862, Brazil e-mail: pso@unicamp.br 